\title{
A Comparative Review of Power Systems Faults Prediction Models
}

\author{
Ganiyu Adedayo Ajenikoko ${ }^{1} \quad$ Bolarinwa Samson Adeleke $^{2} \quad$ Abass Balogun $^{3} \quad$ Adenle Musibau Shittu $^{4}$ \\ 1,2,3,4 Department of Electronic and Electrical Engineering, Ladoke Akintola University of Technology, \\ P.M.B, 4000, Ogbomoso, Nigeria \\ ${ }^{2}$ Department of Electrical Engineering, Adeseun Ogundoyin Polytechnic, P.M.B 1015, Eruwa, Oyo State Nigeria
}

\begin{abstract}
Electrical faults such as in short circuit conditions in power systems result to outages which minimize the reliability of electrical power system due to the equipment failures such as transformers, human error, rotating machines and environmental conditions. These hindering the flow of electricity, damage to equipment and cause death of humans and animals. In view of these, a fault study is routinely performed by utility engineers. However, there were several methods employed by researchers to monitor the states of some important components in power network such as switchgear and transformers, likewise to predict the fault details in all parts of power system. Thus, in this study, different approaches of fault prediction model of power system employed by researchers were reviewed. These approaches have become powerful tools to mitigate the problem of fault occurrence in power system because these tests are carried out more frequently by utilities. This study therefore will help in future planning and smooth operation of the power system and encourage concerned authority to take adequate steps to guide against the predicted faults details in power system.
\end{abstract}

Keywords: Electrical Fault, Reliability, Power System, Short Circuit, Utilities, Equipment Failure

DOI: $10.7176 / \mathrm{CEIS} / 12-3-02$

Publication date: November $30^{\text {th }} 2021$

\section{Introduction}

Faults in electric power system occur as a result of power flow through an undesired path [1]. These undesired path result in sudden flow of current beyond the accepted capacity limit of the power equipment. The faults occur due to flashover, physical damages and insulation failure. These faults are 3-phase in nature comprised all 3-phases in a symmetrical manner or asymmetrical in nature in which only one or two phases are involved. Faults could be caused between live conductors or short circuits to earth in either one or more phases. They can be detected and mitigated fast with a good system protection in order to avoid equipment damage and power outage [2], [3] [22].

The abnormal condition of a fault resulted in reduction of insulation strength between earth and phase conductors [4]. This reduction is considered as a fault when it results in excessive current or reduction in the impedance between conductors to the circuit. Electrical power system includes; switchgears, transformer, generators, power receivers, transmission and distribution circuits and it likely that failures may occur in the system especially in transmission and distribution lines as a results of the widely branched electrical power lines. Also, most of the powers lines are operate at variable weather conditions subjected to the action of atmospheric discharges [5], [6], [7].

Faults in power system depend loading conditions of power system comprise of line voltages and currents which are grouped into two (2) main groups: symmetrical or asymmetrical. Symmetrical voltage and currents occur if all the line currents and voltages maintain their phase shifts at equal magnitudes while asymmetry in a power system occur as a result of load imbalances in the system. However, majority of faults occurring on power network are asymmetrical in nature [8]. Types of faults normally arising on power network are; line to line fault, single line to ground fault, line to line to ground fault and three phase faults. The single lines to ground fault, line to line to ground fault and line to line fault and asymmetrical in nature while three phase fault is symmetrical [8], [9] [24].

A fault is said to be an abnormal condition resulted in reducing the basic insulation strength between phases or line conductors. Such reduction is considered as a fault when it resulted in reduction of the impedance to the circuit or $\mathrm{n}$ an excessive current between conductors and earth. Fault arises due to breakdown of the system insulation by lightning stroke on overhead lines or by connection with earth [6], [10], [11], [45],[48].

\subsection{Causes of Electrical Faults}

The causes of faults can be internal or external, they include the following [1], [6], [7],[29],[31]:

i. Lightning: This is a visible electric discharge between a rain cloud and the earth or between rain clouds. The discharge is presented in form of a arc and stretching between the discharge points. The discharge produces a sound wave called thunder. Majority of rain clouds are negatively and positively charge at the base and top respectively. There are different hypotheses which explain the occurrence of polarization, 
some require ice and some do not. However ice is a obligatory factor, because lightning is usually observed when ice formed in the top layers of thundercloud. Many of the electrical faults on overhead power lines are caused by lightning. Installation of line arrestor becomes a better option to prevent the flashover of insulator assemblies.

ii. Pollution: This is always occurring as a result of continuous deposit of cements dust especially in industrial areas. A high degree of pollution on an insulator assembly reduces the insulation strength of the affected phase, thereby creating a path for current to flow across the insulator assembly, which in turn results in excessive current or other detectable abnormality.

iii. Wildfires: Wildfire occurs closed to electrical power line Right-of-Way (ROW), in which wood poles get burnt. The steel towers used to carry electric lines are also vulnerable to heat. Both wood and steel conductor carrying transmission lines are exposed to physical damage from a wildfire, and the damages done to conductor are not repairable. A fire can cause a forced outage of electrical power circuit if the ambient temperature of the air around the conductor's increases above the line's operating limits. Intense smoke from a nearby wildfire may contaminate an electrical line's insulating medium. This may result to a phase-to-phase fault due to the ionization of air around the conductor.

iv. Ageing: Aging of electrical insulation system is irreversible changes of the properties of an electrical insulation system. The most ageing sensitive part of electrical equipment that determines its useful lifetime is insulation system. External and internal factors determined the total lifetime of electrical equipment. The main internal factor is the operating temperature and the external factors are: overvoltage, vibration, humidity, radiation and other factors (Anderson, 1995). Ageing stresses includes; intrinsic and extrinsic ageing. The formal is the irreversible changes in electrical insulation system properties due to the action of ageing factors. The latter is the irreversible changes in electrical insulation system properties due to the on unintentionally introduced imperfections in the electrical insulation system.

\subsection{Consequences of Faults}

When major fault is left uncleared, it may result to fire outbreak which destroy power system equipment, and result in total failure of the entire system. The consequences of fault are given as: [12], [18], [38],[39]:

i. An abnormal line voltage reduction over other part of the power system, resulting in major breakdown in distributing electrical supply to the end user.

ii. When short circuit occurs electrical arc accompanies it resulting in the damaging of apparatus within the electrical network.

iii. Due to overheating and mechanical forces, fault causes damage to the other apparatus in electrical system.

iv. Stability of the electrical power is affected and could lead to a full blackout of a power system.

v. A significant reduction of voltage on electric feeders having fault may cause abnormal currents to be drawn by motors therefore causing loss of industrial production.

\subsection{Types of Faults}

Faults in a power network occur as results of electrical insulation failure due to flashover, or physical damage. These faults may either be 3-phase when all the phases are short circuited in a symmetrical or asymmetrical manner when only one or two (2) phases are involved [13]. Generally, faults are categorized as shunt faults and series faults. Shunt faults can occur as [14], [15]:

i. $\quad$ Single Line-to-ground fault (SLG): This occurs when conductor falls to ground or contacts the neutral wire.

ii. Line-to-Line fault (LL): Occur when two conductors are short-circuited.

iii. Double Line-to-Ground fault (LLG): Occur when a tree falling on two line of the power system.

iv. Balanced three phase fault (LLL): Fault condition in which all the phases are short circuited.

v. Line-Line-Line-Ground fault (LLLG): This occurs when a tree falls on three power lines.

According to Santamaria, (2011), Series faults occur along the power lines when one or two lines are broken along the distribution network which resulted to unbalanced series impedance [40]. This is referred to as 'single phasing' condition in the power system [1]. Figure 1 shows different types of series faults in power system [16]. 
b)

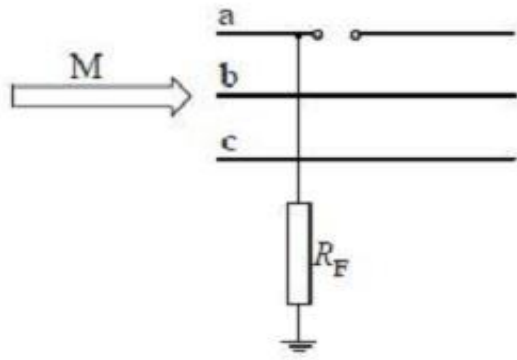

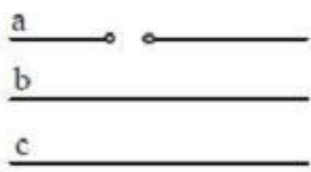

c)

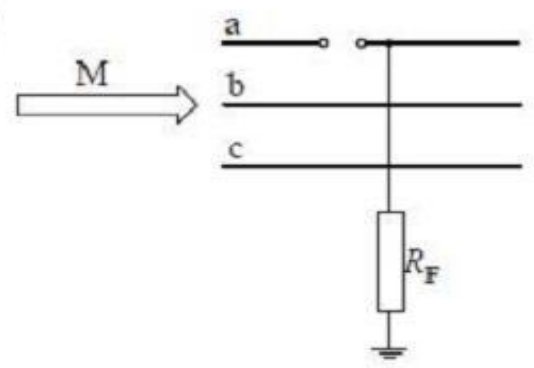

Figure 1: (a) Broken Conductor Failure Alone, (b) Line-to-Ground Fault Broken Conductor, (c) Line-to-Ground Fault Broken Conductor

\section{Analysis of Three phase symmetrical faults}

In analyzing three phase symmetrical faults using sequence network, Glover and Sarma (1994) made the following assumptions [16]:

i. $\quad$ Power system operates before occurrences of fault under balanced steady-state conditions.

ii. Neglecting of the pre-fault load current: When neglecting pre-fault load currents, voltage drops in the pre-fault circuit at each bus in the positive-sequence network is zero and equals to $V_{F}$.

iii. Neglecting the shunt admittances and transformer winding resistances.

iv. Neglecting the shunt admittances and overhead line series resistances.

v. Neglecting armature resistance, saliency and saturation and all non-rotating impedance loads.

vi. Represent the induction motors as synchronous machines.

vii. Three lines are represented by Red (R), Yellow (Y) and Blue (B) and their currents are: $\mathrm{I}_{\mathrm{r}}, \mathrm{I}_{\mathrm{y}}$ and $\mathrm{I}_{\mathrm{b}}$ respectively.

\subsection{Three Phase Fault Model}

Figure 2 below presented the three-phase model of type of fault in power system. Phases R, Y, B are assumed to be short-circuited in all phase with fault impedance $Z_{\mathrm{F}}$. However, there is no connection to earth and this makes it not to be affected with fault currents [17], [18].

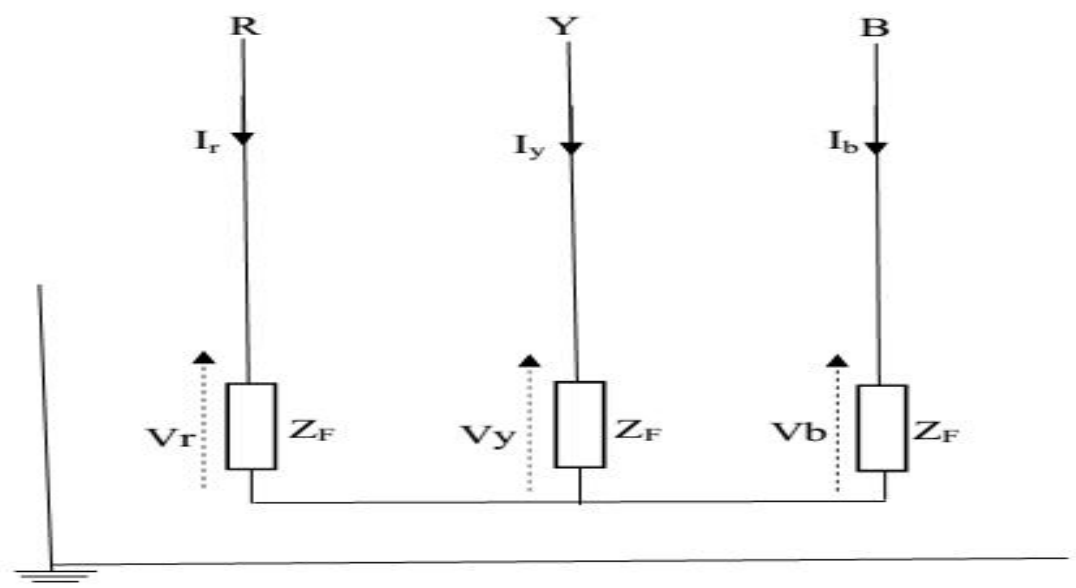

Figure 2: Model of Three Phase Fault

The fault model shown in Figure 2 is symmetrical and fault currents are given as [7]:

$$
\begin{aligned}
& \mathrm{I}_{\mathrm{r}}=\mathrm{I} \\
& \mathrm{I}_{\mathrm{y}}=\mathrm{a}^{2} \mathrm{I} \\
& \mathrm{I}_{\mathrm{b}}=\mathrm{aI}
\end{aligned}
$$

Symmetrical components of three currents are calculated as [2]: 
Thus:

$$
\begin{gathered}
{\left[\begin{array}{l}
I_{0} \\
I_{1} \\
I_{2}
\end{array}\right]=\frac{1}{3}\left[\begin{array}{ccc}
1 & 1 & 1 \\
1 & a & a^{2} \\
1 & a^{2} & a
\end{array}\right]\left[\begin{array}{c}
0 \\
a^{2} I \\
a I
\end{array}\right]=\left[\begin{array}{l}
0 \\
I \\
0
\end{array}\right]} \\
\mathrm{I}_{1}=\mathrm{I} \neq 0 \\
\mathrm{I}_{2}=\mathrm{I}_{0}=0
\end{gathered}
$$

Voltage drops across fault impedance is given as [20]:

$$
\begin{aligned}
& \mathrm{V}_{\mathrm{r}}=\mathrm{Z}_{\mathrm{F}} \mathrm{I}_{\mathrm{r}} \quad=\mathrm{Z}_{\mathrm{F}} \mathrm{I} \\
& \mathrm{V}_{\mathrm{y}}=\mathrm{Z}_{\mathrm{F}} \mathrm{I}_{\mathrm{y}}=\mathrm{a}^{2} \mathrm{Z}_{\mathrm{F}} \mathrm{I} \\
& \mathrm{V}_{\mathrm{b}}=\mathrm{Z}_{\mathrm{F}} \mathrm{I}_{\mathrm{b}} \quad=\mathrm{a} \mathrm{Z}_{\mathrm{F}} \mathrm{I}
\end{aligned}
$$

Estimating symmetrical components of three phase voltages, that is $(2.7 \mathrm{a})$ to $(2.7 \mathrm{c})$, the result is:

This produces

$$
\left[\begin{array}{l}
V_{0} \\
V_{1} \\
V_{2}
\end{array}\right]=\frac{1}{3}\left[\begin{array}{ccc}
1 & 1 & 1 \\
1 & \mathrm{a} & a^{2} \\
1 & \mathrm{a}^{2} & \mathrm{a}
\end{array}\right]\left[\begin{array}{c}
Z_{F} I \\
Z_{F} a^{2} I \\
Z_{F} a I
\end{array}\right]=\left[\begin{array}{c}
0 \\
Z_{F} I \\
0
\end{array}\right]=\left[\begin{array}{c}
0 \\
Z_{F} I_{1} \\
0
\end{array}\right]
$$

$$
\begin{array}{ll}
\mathrm{V}_{1}=\mathrm{Z}_{\mathrm{F}} \mathrm{I}_{1} & \neq 0 \\
\mathrm{~V}_{2}=\mathrm{V}_{0} & =0
\end{array}
$$

Equations (3) to (8) showed that only positive sequence network are used for fault current calculations when considering 3-phase symmetrical fault, negative and zero sequence are of no importance as depicted in Figure 3. Equivalent positive-sequence network shown in Figure 3(b) has a Thevenin equivalent impedance and voltage source with the pre-fault voltage $V_{F}[19]$.

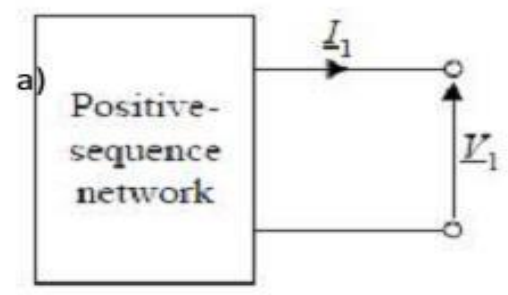

b)

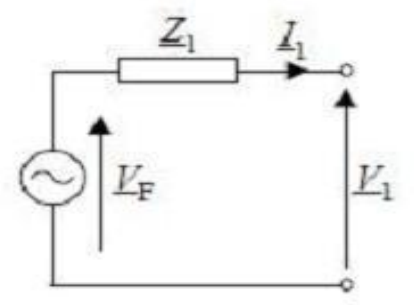

Figure 3: a) General Network, b) Thevenin Equivalent as viewed from Fault Terminals

\section{Analysis of Unsymmetrical Faults}

In the analysis of unsymmetrical faults, three types are considered. They are [19], [20]:
i. line to earth fault
ii. line to line fault
iii. Double lines to earth fault.

\subsection{Line to Earth fault}

By considering a line to earth fault: $\mathrm{R}-\mathrm{E}$ fault shown in Figure 4 . It is assumed that a fault impedance $Z_{F}$ is involved in this fault [21].

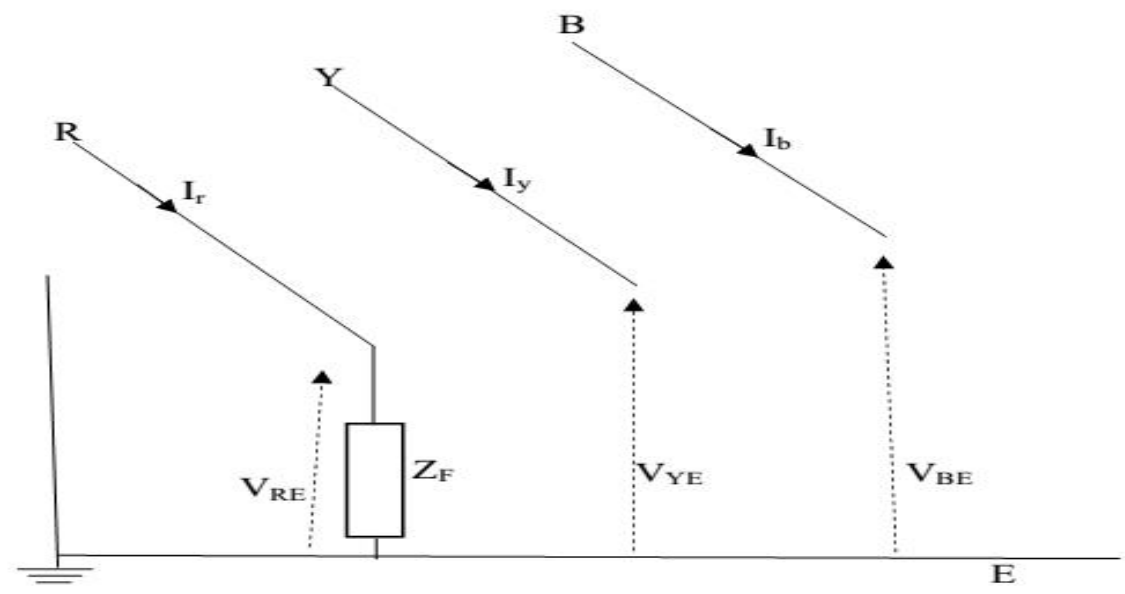

Figure 4. Line to Earth Fault: R-E Fault 
Fault conditions are as follows: [4]

$$
\begin{gathered}
I_{y}=I_{b}=0 \\
V_{R E}=Z_{F} I_{r}
\end{gathered}
$$

Transforming (9) and (10) to sequence domain [7]:

$$
\begin{aligned}
& {\left[\begin{array}{l}
I_{0} \\
I_{1} \\
I_{2}
\end{array}\right]=\frac{1}{3}\left[\begin{array}{ccc}
1 & 1 & 1 \\
1 & a & a^{2} \\
1 & a^{2} & a
\end{array}\right]\left[\begin{array}{c}
I_{r} \\
0 \\
0
\end{array}\right]} \\
& \mathrm{V}_{\mathrm{RE}}=\mathrm{V}_{0}+\mathrm{V}_{1}+\mathrm{V}_{2}=\mathrm{Z}_{\mathrm{F}}\left(\mathrm{I}_{0}+\mathrm{I}_{1}+\mathrm{I}_{2}\right)
\end{aligned}
$$

From (11) and (12), one obtains [10]:

$$
\begin{aligned}
\mathrm{I}_{0}= & \mathrm{I}_{1}=\quad \mathrm{I}_{2}=\frac{1}{3} I_{r} \\
& \left(\mathrm{~V}_{0}+\mathrm{V}_{1}+\mathrm{V}_{2}\right)=\left(3 \mathrm{Z}_{\mathrm{F}}\right) \mathrm{I}_{0}=\left(3 \mathrm{Z}_{\mathrm{F}}\right) \mathrm{I}_{1}=\left(3 \mathrm{Z}_{\mathrm{F}}\right) \mathrm{I}_{2}
\end{aligned}
$$

Equations (13) and (14) are interpreted in the sequence network shown in Figure 5.

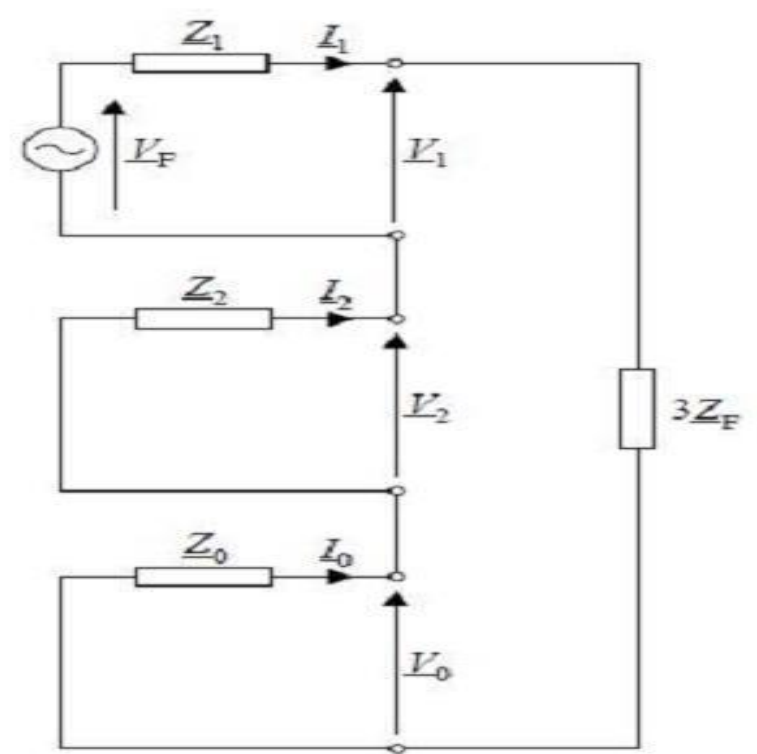

From Figure 5, one has

Figure 5: Interconnected Sequence Networks for R-E Fault

In phase domain,

$$
\mathrm{I}_{0}=\mathrm{I}_{1}=\mathrm{I}_{2}=\frac{V_{F}}{Z_{0}+Z_{1}+Z_{2}+3 Z_{F}}
$$

$$
\begin{gathered}
\mathrm{I}_{\mathrm{r}}=\mathrm{I}_{0}+\mathrm{I}_{2}+\mathrm{I}_{3}=3 \mathrm{I}_{1}=\frac{3 V_{3}}{Z_{0}+Z_{1} Z_{2}+3 Z_{F}} \\
\mathrm{I}_{\mathrm{y}}=\mathrm{I}_{0}+\mathrm{a}^{2} \mathrm{I}_{1}+\mathrm{aI}_{2}=\left(1+\mathrm{a}^{2}+\mathrm{a}\right) \mathrm{I}_{0}=0 \\
\mathrm{I}_{\mathrm{b}}=\mathrm{I}_{0}+\mathrm{aI}_{1}+\mathrm{a}^{2} \mathrm{I}_{2}=\left(1+\mathrm{a}+\mathrm{a}^{2}\right) \mathrm{I}_{0}=0
\end{gathered}
$$

A sequence component of the line to earth voltages at the fault is given as in [6]:

Therefore line to earth voltages is:

$$
\left[\begin{array}{l}
V_{0} \\
V_{1} \\
V_{2}
\end{array}\right]=\left[\begin{array}{c}
0 \\
V_{F} \\
0
\end{array}\right]-\left[\begin{array}{ccc}
Z_{0} & 0 & 0 \\
0 & Z_{1} & 0 \\
0 & 0 & Z_{2}
\end{array}\right] \cdot\left[\begin{array}{l}
I_{0} \\
I_{1} \\
I_{2}
\end{array}\right]
$$

$$
\left[\begin{array}{l}
V_{R E} \\
V_{Y E} \\
V_{B E}
\end{array}\right]=\left[\begin{array}{ccc}
1 & 1 & 1 \\
1 & a^{2} & a \\
1 & a & a^{2}
\end{array}\right] \cdot\left[\begin{array}{l}
V_{0} \\
V_{1} \\
V_{2}
\end{array}\right]
$$

\subsection{Line to Line fault}

By considering a line-to-line fault: Y-B fault, as shown in Figure 6. It is assumed that a fault impedance $\mathrm{Z}_{\mathrm{F}}$ is involved in this fault. Fault condition in line domain [8]: 


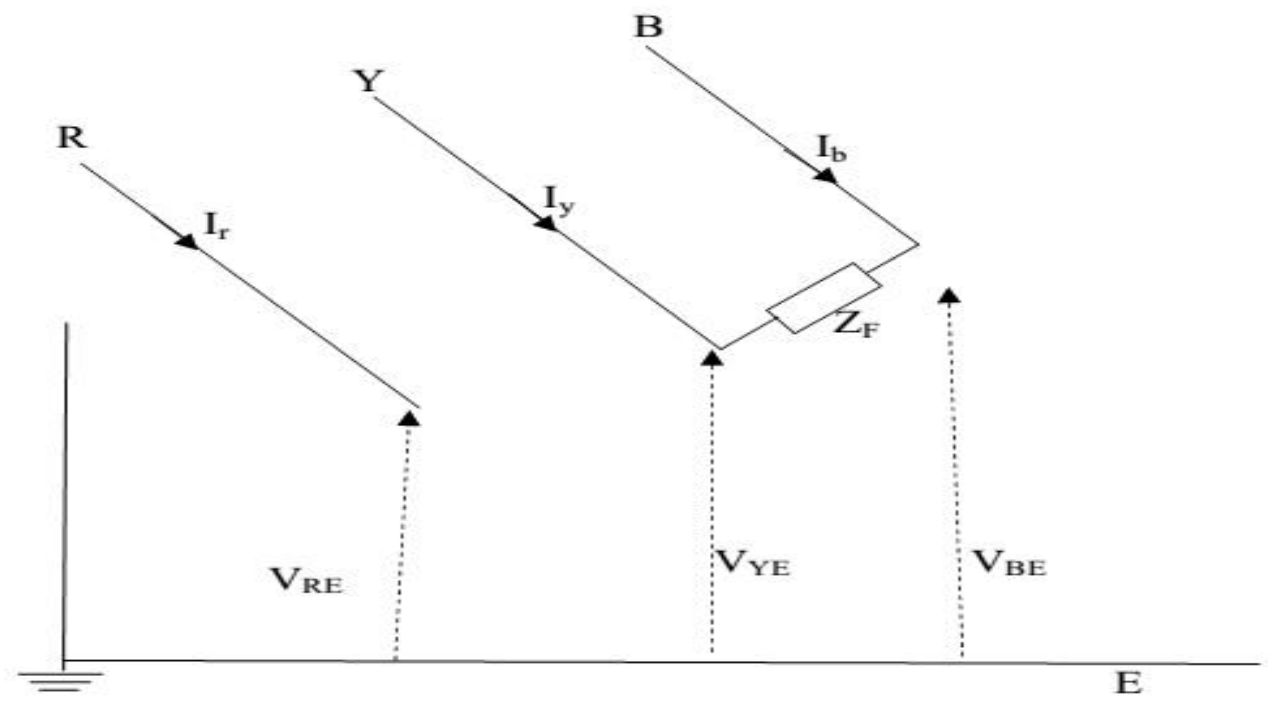

Figure 6: Line to Line Fault from Line ' $\mathrm{Y}$ ' to 'B' (Y-B fault).

$$
\begin{aligned}
& I_{r}=0 \\
& I_{b}=-I_{y} \\
& V_{Y E}-V_{B E}=Z_{F} I_{Y}
\end{aligned}
$$

Transforming equations (22) to (24) to the sequence domain as:

From (25),

$$
\left[\begin{array}{l}
I_{0} \\
I_{1} \\
I_{2}
\end{array}\right]=\frac{1}{3}\left[\begin{array}{ccc}
1 & 1 & 1 \\
1 & a & a^{2} \\
1 & a^{2} & a
\end{array}\right] \cdot\left[\begin{array}{c}
0 \\
I_{y} \\
I_{y}
\end{array}\right]
$$

$$
\begin{aligned}
& \mathrm{I}_{0}=0 \\
& I_{1}=\frac{1}{3}\left(a I_{y}-a^{2} I_{y}\right)=\frac{1}{3}(a-a)^{2} I_{y} \\
& I_{2}=\frac{1}{3}\left(a^{2} I_{y}-a I_{y}\right)=\frac{1}{3}\left(a^{2}-a\right) I_{y}=-I_{1}
\end{aligned}
$$

Voltage drop across the fault path impedance is[22]:

$$
\begin{aligned}
& {\left[\begin{array}{l}
V_{R E} \\
V_{Y E} \\
V_{B E}
\end{array}\right]=\left[\begin{array}{ccc}
1 & 1 & 1 \\
1 & a^{2} & a \\
1 & a & a^{2}
\end{array}\right] \cdot\left[\begin{array}{l}
V_{0} \\
V_{1} \\
V_{2}
\end{array}\right]} \\
& \quad\left(V_{Y E}-V_{B E}\right)=Z_{F}\left(I_{0}+a^{2} I_{1}+a I_{2}\right)
\end{aligned}
$$

Left hand side of (30) equals:

$$
V_{Y E}-V_{B E}=\left(V_{0}+a^{2} V_{1}+a V^{2}\right)-\left(V_{0}+a V_{1}+a^{2} V_{2}\right)=\left(a^{2}-a\right) V_{1}-\left(a^{2}-a\right) V_{2}
$$

Right hand of (30) equals:

$$
Z_{F}\left(I_{0}+a^{2} I_{1}+a I_{2}\right)=Z_{F}\left(0+a^{2} I_{1}-a I_{1}\right)=Z_{F}\left(a^{2}-a\right) I_{1}
$$

Comparing (31) and (32) its outcome is:

$$
\left(a^{2}-a\right) V_{1}-\left(a^{2}-a\right) V_{2}=Z_{F}\left(a^{2}-a\right) I_{1}
$$

Therefore,

$$
V_{1}-V_{2}=Z_{F} I_{1}
$$

In addition, Figure 7 presented the interconnected sequence network of line to line fault. Though zero sequence may be omitted since there is no flow of current in the network $\left(I_{0}=0\right)$ [22], [23]. 


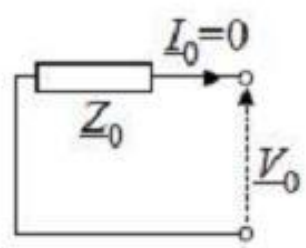

a

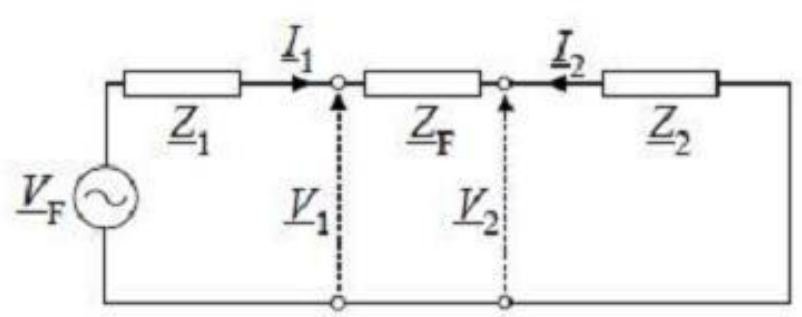

b

Figure 7: Interconnected Sequence Networks for Line to Line Fault from Line ' $\mathrm{Y}$ ' to 'B'(Y-B Fault)

From Figure 7, this is obtained [23] [29]:

$$
I_{1}=I_{2}=\frac{V_{F}}{\left(Z_{1}+Z_{2}+Z_{F}\right)}
$$

When equation (35) is transformed into phase domain, knowing that $a^{2}-a=-j \sqrt{3}$, current in the faulted line (line $\mathrm{Y}$ ) equals:

$$
\begin{aligned}
& I_{y}=I_{0}+a^{2} I_{1}+a I_{2}=\left(a^{2}-a\right) I_{1}=-j \sqrt{3} I_{1}=\frac{-j \sqrt{3} V_{F}}{\left(z_{1}+Z_{2}+Z_{F}\right)} \\
& I_{r}=I_{0}+I_{1}+I_{2}=0 \\
& I_{b}=I_{0}+a I_{1}+a^{2} I_{2}=\left(a^{2}-a\right) I_{1}=-I_{y}
\end{aligned}
$$

The sequence components of line to line fault voltages at fault are calculated as [23]:

$$
\left[\begin{array}{l}
V_{0} \\
V_{1} \\
V_{2}
\end{array}\right]=\left[\begin{array}{c}
0 \\
V_{F} \\
0
\end{array}\right]-\left[\begin{array}{ccc}
Z_{0} & 0 & 0 \\
0 & Z_{1} & 0 \\
0 & 0 & Z_{2}
\end{array}\right] \cdot\left[\begin{array}{l}
I_{0} \\
I_{1} \\
I_{2}
\end{array}\right]
$$

\subsection{Double Line to Earth fault}

Figure 8 shows double lines to fault occurrence [24] [32], [35].

Fault conditions are [24]:

$$
\begin{aligned}
& I_{r}=0 \\
& V_{B E}=V_{Y E} \\
& V_{Y E}=Z_{F}\left(I_{y}+I_{b}\right)
\end{aligned}
$$

Transforming (40) to sequence domain [37]:

$$
I_{1}+I_{2}+I_{0}=0
$$

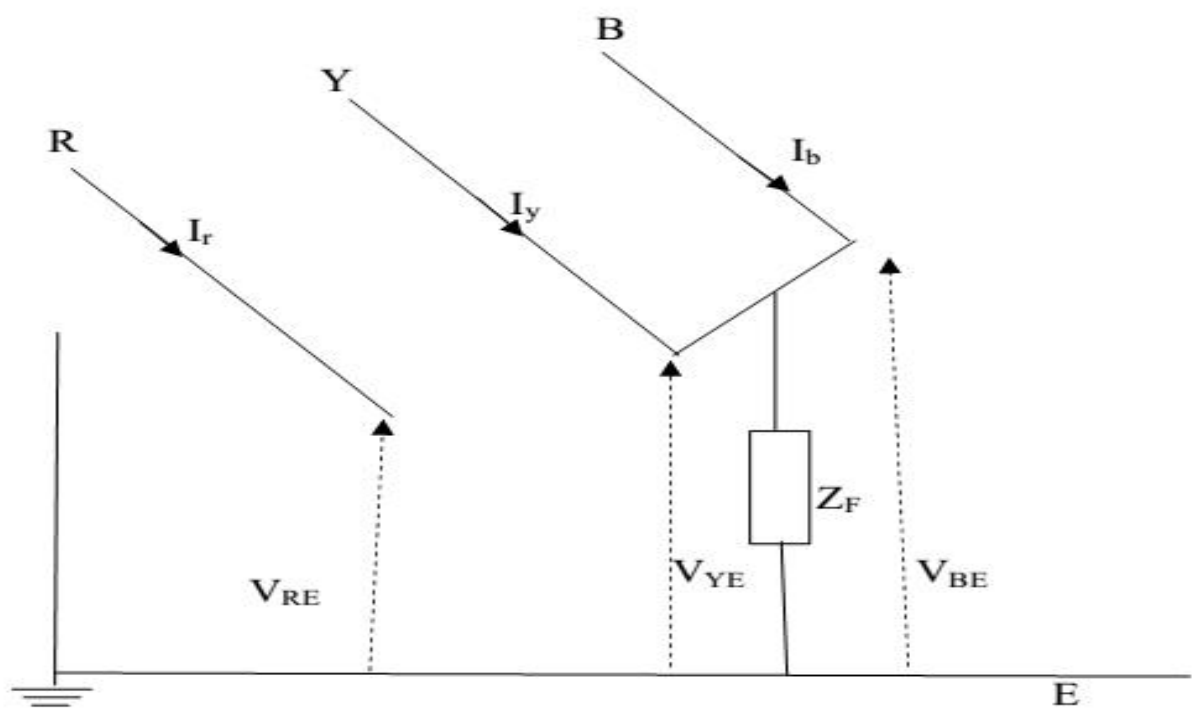

Figure 8: Double Line to Earth Fault from Line ' $\mathrm{Y}$ ' to ' $\mathrm{B}$ ' and to Earth (Y-B-E fault) 
Taking equation (43) one obtains [23]:

Using equation (42):

$$
\left(a^{2}-a\right) V_{2}=\left(a^{2}-a\right) V_{1} \text { or } V_{2}=V_{2}
$$

$$
V_{0}+a^{2} V_{1}+a V_{2}=Z_{F}\left(I_{0}+a^{2} I_{1}+a I_{2}+I_{0}+a I_{1}+a^{2} I_{2}\right)
$$

Since $\left(a^{2}+a\right)=-1$, equation (45) becomes[39], [45]:

$\begin{array}{cc} & V_{0}-V_{1}=Z_{F}\left(2 I_{0}\right. \\ \text { From equation (43), } & I_{0}=-\left(I_{1}+I_{2}\right)\end{array}$

$$
\begin{aligned}
& I_{0}=-\left(I_{1}+I_{2}\right) \\
& V_{0}-V_{1}=3 Z_{F} I_{0}
\end{aligned}
$$

\section{Intelligent System}

Occurrence of faults in electrical power system supply is inevitable, but with a well-coordinated protection system, the faults will be able to detect and isolate fault to avoid damage to equipment. To protect power system transmission lines, the faults must be isolated accurately. The control centre of a power network contains large number of alarms which receive signals from protection schemes for various fault. These faults are grouped into balanced and unbalanced faults. Different methods are used for their diagnosis on the transmission line and power system at large. One of the intelligent systems widely used for different areas of analysis is artificial neural network [25], [37].

According to Dalstein and Kulicke (1995), a comprehensive scheme for fault diagnosis on transmission and distribution lines system should accomplish the following three tasks [9]:

i. Fault Detection: The generated line voltage and current which are on per - unit values were sampled with the target values into the input neurons of the selected ANN, trained and produced outputs of different types of fault detected on the transmission/ distribution line.

ii. Fault Classification: Here, a second neural network is employed to differentiate the fault. It receives the line currents and voltages as inputs. The output of the network has four signals to differentiate the four classes of fault which are line-to-line fault, line-to-ground fault, double line-to-ground fault and three phase fault.

iii. Fault Isolation: The third neural network is used to localize the faults on the transmission/ distribution line according to the feeder.

\section{Review of Related Works}

Many research works have been carried out on fault Studies on power system, some of them are reviewed as follows:

Borghetti et al. (2007) [7] made a comparison between two methods of fault-location in distribution system based on a single-ended measurement system. The two methods were reviewed and compared using EMTP simulation for a medium voltage network configuration. The complimentary characteristic of the two methods suggested the analysis of a hybrid approach considering start-time and wavelet analysis of voltage transients. The paper showed that method "A" located the lateral where the fault occurred and method B estimated the location of fault on the identified lateral. Hybrid approach resulted in less expensive system compared to method "A' and more efficient compared to method "B".

Demetrios (2009) [10] presented a short circuit faults calculation for a complex system faults and operating conditions. The study provided power engineer with information on proper relay settings and operations. The study thereby derived the symmetrical component equivalent for an unbalanced transformer bank. At the end, the magnitude of the circulating current in the tertiary winding of the unbalanced transformer bank agreed very closely with the results of automatic transient programme (ATP).

Gorinevsky et al. (2009) [19] demonstrated an optimization approach to estimate DC power system fault using regularization of a sparse fault vector. The approach was implementation and demonstrated on an instrumented electrical power system test bed at NASA. ADAPT test bed was use for simulation and the data from the first set were called "Observer" data and the second as "Antagonist" data. The Observe data are used for testing diagnostic algorithms while Antagonist data was used in creating fault conditions for the Observer. The approach was suitable for online implementation of monitoring applications for electric power systems.

Faig et al., (2010) [13] employed the influence of Distributed Generation (DG) method to analyze faults in power distribution system using impedance-based fault location. Application was developed in MATLAB/Simulink to simulation and for extraction of electrical data from a database. The presence of DG in a power distribution network decreases the value of the apparent reactance in the distribution substation. Thus, the obtained results were closer than the actual location of the fault in the system.

Faradonbeh et al. (2011) [14] outlined impedance based technique for determining the fault location in a distribution network. The algorithm of the impedance based technique was developed and integrated into PSCAD/EMTDC software by using C-interface and FORTRAN Language and implemented on a Canadian 
distribution network. The correlation between fault distances and apparent impedance were studied. The results showed that as the fault distance increased the apparent reactance was increasing.

Bunnoon (2013) [8] proposed the use of state-of-the-art article reviews to analyze fault detection in power system. The author reviewed many papers to develop an approach for appropriate fault detection by enumerating different types of approaches ( such as; Bridge circuit method, Surface wave, Petri nets, Wavelet transform approach, Neural network approach, Artificial intelligence (Fuzzy, Genetic), Graph methodology Real-time and Statistical methodology) and their area of applications. The author concluded that the fault detection in system was faster in the transmission line, transformer, or anywhere in the electricity system.

Kakalli (2013) [26] presented system analysis with Mega Volts Ampere (MVA) algorithm for symmetrical 3-phase faults. The performance of the system was simulated in transient stability analysis under a variety of disturbances. The author highlighted the causes of faults as: insulation failure, a conducting material coming in contact with a bare conductor, lightning and vehicular collision with the poles or towers.

Nath and Balaji (2013) [34] examined different types of sags caused by different types of faults using 110 $\mathrm{kV}$ distribution networks. Results showed that sag distributions were highly dependent on the power system characteristics.

Oyetunji (2013) [36] developed an algorithm that distinguished between overload and short circuit currents. The algorithm was simulated in MATLAB before field deployment on Akure Electric Power Distribution System (EPDS). The acquired information was analysed and diagnosed at DCC to determine the status of the network. Thus, integration of real time diagnostic system to the EPDS improved the power availability.

Kaur et al. (2014) [27] presented analysis of short circuit fault on electrical power network using MATLAB software. IEEE 11 and 30-bus power system were used as case studies. Pre-fault calculations were done and 3phase short circuit fault was simulated on the test system. The total fault current, voltage magnitude and fault voltage phase angle at each bus and fault current flows in the lines were determine. Results obtained showed a rapid reduction on voltage magnitude at faulty buses while the fault current flow in the lines were increased.

Kehinde et al., (2014) [28] carried out a fault analysis of $33 \mathrm{kV}$ Ekiti State distribution system. Power availability in the $33 / 11 \mathrm{kV}$ injection stations in the state was considered by collecting energy supplied data, faults and other outages. The outcome of the research indicated that the probability of having two consecutive hours of power was less than $25 \%$ in a year, indicating a very poor situation for consumers.

Md Asaduzzaman et al. (2014) [30] developed a microcontroller-based protection technique for effective monitoring and control of distribution network. It consisted of GSM networking, designed to send data from Distribution side to the Sub-station and a MATLAB GUI system was developed to show the data. A MATLAB GUI consisting of transformer, microcontroller ATMEGA16, GSM module and bridge rectifier circuits were designed and simulated in PROTEUS. GSM based microcontroller protection system was reliable and cost effective solution for monitoring the electric distribution network.

Gamit et al., (2015) [15] designed a reclosing mechanism for permanent or temporary fault. The Timer Integrated circuit IC-555 was employed for time duration data of the fault. Circuit breaker was employed for disconnecting the line at fault instant and connecting on clearance of fault. MATLAB software was used to simulate the system. When signal was given to the switch, it closed and fault occurred in the system and at that instant, circuit breaker was operated and disconnected the system from faulty part. Different voltage unbalance was observed. The faults were taken temporary as well as permanent.

Moura et al. (2015) [33] presented equations and equivalent circuit approach for fault detection in power system using software ANAFAS for validation of the methodology. The results established that the equivalent circuit approach can substitute as the equivalent circuits for single line-to-ground fault and a bolted line-to-line fault (SLG-BLL-F) calculation.

Seetharamayya and Venkateswara (2015) [42] evaluated symmetrical fault analysis on voltage and current in a power system using Newton-Raphson load flow method. The simulation was carried out on each bus of the IEEE 30 bus power system, by calculating the fault voltage magnitude at each bus. The SCMVA ratings based on the fault currents on each bus and line and then the corresponding circuit breaker ratings were chosen.

Sica et al. (2015) [43] presented an intelligent approaches based on cognitive systems for fault prognosis in power transformers by combined both evolutionary and connectionist mechanisms into a hybrid model for a predictive maintenance technology to prevent or reduce unplanned reactive maintenance. The results showed that the system predicted correctly not only the type of fault but also when that fault was expected to occur. The prediction is useful for System Health Management.

Suparna and Aritras (2015) [44] examined the effect of fault on the stability of a power system. IEEE14 bus system in MATLAB Simulink was employed by drawing each area in subsystem block. The study concluded that fault occurs in any of the subsystem, all the system voltages and system currents are affected and must be improved otherwise it would create fault of circuit parameters to other lines. However, if faulty lines were not improved, or disconnected from healthy area, then huge crisis of power would occur such as total blackouts.

Zhang and Kezunovic (2015) [47] introduced fault analysis simulation software based on the MATLAB and 
alternative transient program (ATP) simulation. The software is of two major: power system simulation and relay algorithm evaluation. The former automatically generate thousands of system-wide events at one time and extracted the transients for fault studies. The latter included the traditional distance relay model and two new advanced fault diagnosis algorithms. The software benefited from both programming flexibility of MATLAB and simulation efficiency of ATP

Agbesi and Okai (2016) [2] introduced a smart Global System for Mobile Communications (GSM) based fault detection on power system. Different methods of faults detection were discussed, among were impedance and other fundamental frequency component based methods for detecting faults on transmission lines, high frequency components and travelling wave based methods, knowledge-based method. The system provided a reduction in the time required to locate a fault by automatically providing accurate fault location information especially in the radial system.

Satish and Tripti (2016) [41] proposed a model for faults analysis and identification on $300 \mathrm{~km} / 440 \mathrm{kV}$ EHV transmission lines and simulated in MATLAB software. Simulation was done using MATLAB simulation in computer and the analysis of Maximum voltage transmission line faults was easily detected and analysed. The paper finally established the use of MATLAB software along with the Sim-power system toolbox in Simulink for detection and analysis of faults distance on $300 \mathrm{~km} / 440 \mathrm{kV}$ supply on long transmission line.

Xiuchang et al., (2016) [46] presented an optimal allocation of resistive type superconducting fault current limiters (SFCLs) on a power system based on UK network standards. Two models were used to assess the impact of incorporating SC material on the power system and model in a Heaviside function. Then, a realistic model was used to simulate the operation of an SFCL, taking into consideration the proper E-J characteristics of the superconducting material and dynamic temperature evolution. The study proved that installation of more SFCLs does not necessarily mean better overall performance.

\section{Conclusion}

The study has reviewed different models and methods used for fault analysis on power system. Most of the previous researches were centered on different aspects of faults analysis such as: use of simulation module to analyze different types of faults, use of distribution generation method to analyze faults in power distribution system, development of an algorithm to differentiate between overload current and short circuit current, examined different types of sags caused by different types of faults, presentation of intelligent based system for fault prognosis, comparative study of faults on distribution system, design of a reclosing mechanism for permanent and temporary faults, estimation of fault current and voltage in a symmetric power network and other related topics. These reviews have been addressed to show fundamental achievements on fault prediction analysis in power system. This study will therefore, help in future planning and smooth operation of the substation and encourage concerned authority to take adequate steps to guide against the occurrence of faults hence giving an indication of the performance of the power generators over time.

\section{References}

[1] Adegboyega, G. A. and Onime, F. (2013): "Determination of Electric Power Losses in Distribution Systems: Ekpoma, Edo State, Nigeria as a Case Study”, The International Journal of Engineering and Science, 3(1), 2319-1805.

[2] Agbesi, I.K., and Okai, F.A (2016): “Automatic Fault Detection and Location in Power Transmission Lines Using GSM Technology”, International Journal of Advanced Reaserch in Science and Engineering, 5(1):2319-8354.

[3] Ajenikoko, G. A., Eboda, A. W. and Adeleke, B. S. (2019): "Development of a Newton Raphson Symmetrical Component Based Technique for Fault Analysis on Nigerian 330 kV Transmission Lines", Journal of Natural Sciences Research, 9(16): 20-31.

[4] Anderson, J.W. (1995). Technology Transfer Equipment Qualification Methodology for Shelf Life Determination. In: IEEE Transactions on Nuclear Science, 4(42), 1-20.

[5] Anumaka, M. C. (2012). Analysis of Technical Losses in Electrical Power System: Nigerian $330 \mathrm{kv}$ Network as a Case Study", IJRRAS, 12(2): 1-12.

[6] Birolini, A. (2007):“Reliability Engineering: Theory and Practice”. 5th ed., Springer, 2007. ISBN 978-3540-49388-4.

[7] Borghetti, A., Bosetti, M., Di Silvestro, M., Nucci, C.A., Paolone, M., Scala, E., and Tinarelli, R. (2007): "Assessment of Fault Location in Power Distribution Network", Electrical Power and Quality and Utilization Journal, 8(1): 33-41.

[8] Bunnoon, P. (2013): "Fault Detection Approaches to Power System: State-of-the-Art Article Reviews for Searching a New Approach in the Future", International Journal of Electrical and Computer Engineering,3(4): 553-560, ISSN: 2088-8708.

[9] Dalstein, T., and Kulicke, B. (1995): "Neural Network Approach to Fault Classification for High Speed 
Protective Relaying", IEEE Transactions on Power Delivery, 10 (2): 1002-1009.

[10] Demetrios, T. (2009): "Analysis of Complex Power System Faults and Operating Conditions", Proceedings of the63rd Annual Georgia Tech Protective Relaying Conference. Schweitzer Engineering Laboratories, Inc.

[11] Dickert, J., Hable, M. And Schegner, P. (2009): "Energy Loss Estimation in Distribution Networks for Planning Purposes", IEEE Bucharest Power Technology Conference, June $28^{\text {th }}$, Bucharest, Romania, 1-7.

[12] Edward, F (2013): "An overview to power equipment lifetime" Posrerus Portal pre odborne publikovanie, ISSN 1338-0087. 1-9

[13] Faig, J., Melendez, J., Herraiz, S., and Sanchez, J. (2010): "Analysis of Faults in Power Distribution Systems with Distributed Generation", Proceedings of the International Conference on Renewable Energies and Power Quality, 863-868.

[14] Faradonbeh, M.A., Mokhlis, H.B., Karimi, M., and Shahariari, A. (2011): "Balance and Single Line to Ground Fault Location in Electrical Distribution System", Proceedings of the $5^{\text {th }}$ International Power Engineering and Optimization Conference (PEOCO2011), Shah Alam, Selangor, Malaysia.

[15] Gamit, V., Karode, V., Mistry, K., Parmar, P., and Chaudhari, A. (2015): "Fault Analysis on Three Phase System by Auto Reclosing Mechanism, International Journal of Research in Engineering and Technology, 4(5): 292-298, ISSN: 2321-7308.

[16] Glover, J.D. and Sarma M. (1994):"Power System Analysis and Design”, PWS Publishing Company, Boston, Second Edition, 302-308.

[17] Glover, J.D. and Sarma M. S. (2002):"Power Systemand Design”, Brooks/Cole Thomas Learning, USA, Third Edition, 208-212.

[18] Gonen, T. (1987). "Modern Power Analysis". John Wiley and Sons,315-322.

[19] Gorinevsky, D., Boydy, S., and Poll, S. (2009): "Estimation of Faults in DC Electrical Power System", Proceedings of American Control Conference, St. Louis, Missouri.

[20] Grainger, J.J. (2003):“Power System Analysis”. Tata McGraw-Hill, , ISBN 978-0-07-058515-7, $150-190$.

[21] Heine, P. (2003): "Voltage Sag Distributions Caused by Power System Faults", IEEE Transactions on Power Systems, 18(4): 1367-1373.

[22] Idoniboyeobu, D. C. and Udoha, E. E. (2018). Impact of Distributed Generation from Solar Energy on Power System Distribution in Nigeria. IOSR Journal of Electrical and Electronics Engineering (IOSRJEEE), 13(2): 32-47.

[23] Izykowski, J. (2011) Power System Faults, Wrocław University of Technology. Renewable Energy Systems ISBN 978-83-62098-80-4 Published by Printpap Lodz, www.printpap.pl. PhD Thesis. 1.120.

[24] Jie, M. And Xiandong, M. (2018): "A Review Of Forecasting Algorithms And Energy Management Strategies for Microgrids", Systems Science and Control Engineering, AN Open Access Journal 2018 , Vol . 6, No. 1, $237-248$.

[25] Kacejko P., Machowski, J. (2002): "Power System Faults", Scientific-Technical Publisher WNT, Warszawa (in Polish), 98-120.

[26] Kakilli, A. (2013): "System Analysis with the MVA Method for Symmetrical Three-Phase Faults", TEM Journal, 2 (1): 51-56.

[27] Kaur, D., Bath, S.K., and Sidhu, D. S. (2014). Short Circuit Fault Analysis of Electrical Power System using MATLAB, IOSR Journal of Electrical and Electronics Engineering, 9, (2): 89-100.

[28] Kehinde, O., Temitope A., Ayodele S.O., and Adedayo K.B. (2014): "Electrical Fault Analysis of 33 kV Distribution Network: A Case Study of Ekiti State 33kV Distribution Network", American Journal of Engineering Research (AJER), 3(03): 280-286.ISSN: 2320-0936.

[29] Kumara, N. M., Guptab, R. P., Mathewc, M., Jayakumard, A. And Singh, N. K. (2019): "Performance, energy loss, and degradation prediction of roof integrated crystalline solar PV system installed in Northern India", Case Studies in Thermal Engineering 13 (2019) 100409, 1-9.

[30] Md Asaduzzaman N., Mehdi H. S., Muhit,M. S., and Md Khaled, H. (2014): "Fault Analysis and Electrical Protection of Distribution Transformers", Global Journal of Researches in Engineering: Electrical and Electronics Engineering, 14(3): Version 1.

[31] Mehta, V.K., and Mehta, R. (2007).Principles of Power Systems, S.Chand and Company Limited, New Delhi, India, 1-12.

[32] Messalti, S., Zitouni, F., and, Griche, I. (2013). Design of MV/LV Substation Transformer, Scientific Research,5, 20-25.

[33] Moura, A. P., Lopes, J.A.P., and de Moura A.A.F (2015): "Sequence networks to the Calculation of TwoSimultaneous Faults at the Same Location", Electrical Power and Energy Systems, 6(9): 414-420.

[34] Nath, R.P., and Balaji, V.N. (2013): "Artificial Intelligence in Power Systems", IOSR Journal of Computer Engineering (IOSR-JCE), 1-7, e-ISSN: 2278-0661, p-ISSN: 2278-8727.

[35] Ogboh, V. C., and Madueme, T. C. (2015). Theoretical Background to Power System Fault Studies: A 
Novel Method, International Journal of Research in Management, Science \& Technology, 3(4): 150-159.

[36] Oyetunji S. A. (2013):"Real-Time Evaluation of System Dynamics to Improve Network Performance in Akure Electric Power Distribution System in Nigeria”, Journal of Electrical and Electronic Engineering, 3(6): 156-166.

[37] Pali, B. S, Bhowmick, S and Kumar, N. (2015): "Power Flow Models of Static VAR Compensator and Static Synchronous Compensator", IEEE Conference Paper, 5(12), 3-6.

[38] Saadat, H. (2002): "Power System Analysis", Mc-Graw Hill Primis Custom Publishing Company Limited, New Delhi, India. 399-434.

[39] Sahlin, J. (2016): "Line Loss Prediction Based on Regression Analysis on Line Loss Rates and Optimisation Modelling on Nordic Exchange Flows", Examensarbete Inom Energi Och Miljö, Avancerad Niv å 30 HP Stockholm, SVERIGE 2016, 1-94.

[40] Santamaria, J. (2011):"Analysis of Power Systems under Fault Conditions”, California State University, Sacramento. B.S. Universidad Centroamericana, MSc. Dissertation, “Jose Simeon Canas”, El Salvador.

[41] Satish K., and Tripti, B. (2016): "A Modelling of 440kV EHV Transmission Line Faults Identified and Analysis by Using MATLAB Simulation", International Journal of Advanced Research in Electrical, Electronics and Instrumentation Engineering, 5(3), ISSN (Print) : 2320-3765, ISSN (Online): $2278-8875$.

[42] Seetharamayya, K., and Venkateswara,M. R. (2015): "Evaluation of Fault Voltage and Current in a Symmetric Power System Network", International Journal of Innovative Research in Electrical, Electronics, Instrumentation and Control Engineering, 3(8).

[43] Sica, F.C., Guimaraes F. G., Duarted, R.O., and Reise, A. J.R. (2015): “A cognitive system for fault prognosis in power transformers", Electric Power Systems Research, 12(7):109-117.

[44] Suparna, P., and Aritras C. (2015): "Fault and Stability Analysis of a Power System Network by Matlab Simulink", International Journal of Engineering Research and General Science, 3( 3): 222-230, ISSN 20912730.

[45] William, P. D. (2012):“Analysis of Faults in Overhead Transmission Lines”, M.Tech dissertation. California State University, Sacramento, 5-10.

[46] Xiuchang, Z., Harold S.R., Jianzhao G., Boyang, S, Lin F., Heng Z., and Tim, A.C. (2016): "Power Flow Analysis and Optimal Locations of Resistive Type Superconducting Fault Current Limiters", Springer Plus, 5(1972),DOI 10.1186/s40064-016-3649-4.

[47] Zhang, N., and Kezunovic, M. (2015): "Implementing an Advanced Simulation Tool for Comprehensive Fault Analysis", IEEE/PES Transmission and Distribution Conference and Exhibition, Asian and Pacific Dalian, China.

[48] Zydanowicz, J. (1979): "Power System Protection and Control", Scientific- Technical Publisher WNT, Warszawa (in Polish), vol. 1, 2-3. 